\title{
Synthesis and evaluation of a novel antibacterial dental resin composite with quaternary ammonium salts
}

\author{
Yiming Weng ${ }^{1}$, Xia Guo ${ }^{1}$, Voon Joe Chong ${ }^{1}$, Leah Howard ${ }^{1}$, Richard L. Gregory ${ }^{2}$, Dong Xie ${ }^{1}$ \\ ${ }^{1}$ Department of Biomedical Engineering, Purdue School of Engineering and Technology Indiana University-Purdue University at \\ Indianapolis, Indianapolis, USA; \\ ${ }^{2}$ Department of Oral Biology, School of Dentistry, Indiana University Indianapolis, Indianapolis, USA. \\ Email: dxie@iupui.edu
}

Received 16 February 2011; revised 26 February 2011; accepted 1 March 2011.

\begin{abstract}
The novel quaternary ammonium bromide (QAB)containing oligomers were synthesized and applied for developing an antibacterial resin composite. Compressive strength (CS) and S. mutans (an oral bacteria strain) viability were used to evaluate the mechanical strength and antibacterial activity of the formed composites. All the QAB-modified resin composites showed significant antibacterial activity and mechanical strength reduction. Increasing chain length and loading significantly enhanced the antibacterial activity but dramatically reduced the CS as well. The 30-day aging study showed that the incorporation of the QAB accelerated the degradation of the composite, suggesting that the QAB may not be well suitable for development of antibacterial dental resin composites or at least the QAB loading should be well controlled, unlike its use in dental glass-ionomer cements. The work in this study is beneficial and valuable to those who are interested in studying antibacterial dental resin composites.
\end{abstract}

Keywords: QAB; Substitute Chain Length; Antibacterial; S. Mutans Viability; CS; Dental Resin Composites

\section{INTRODUCTION}

Long-lasting restoratives and restoration are clinically attractive because they can reduce patents' pain and expense as well as the number of their visits to dental offices [1-4]. In dentistry, both restorative materials and oral bacteria are believed to be responsible for the restoration failure [2]. Secondary caries is found to be the main reason to the restoration failure of dental restoratives including resin composites and glass-ionomer cements [1-4]. Secondary caries that often occurs at the interface between the restoration and the cavity preparation is primarily caused by demineralization of tooth structure due to invasion of plaque bacteria (acid-producing bacteria) such as Streptococcus mutans (S. mutans) in the presence of fermentable carbohydrates [4]. To make long-lasting restorations, the materials should be made antibacterial. Although numerous efforts have been made on improving antibacterial activities of dental restoratives, most of them have been focused on release or slow-release of various incorporated low molecular weight (MW) antibacterial agents such as antibiotics, zinc ions, silver ions, iodine and chlorhexidine (CHX) [5-9]. Yet release or slow-release can lead or has led to a reduction of mechanical properties of the restoratives over time, short-term effectiveness, and possible toxicity to surrounding tissues if the dose or release is not properly controlled [5-9].

Materials containing quaternary ammonium salt (QAS) or phosphonium salt (QPS) groups have been studied extensively as an important antimicrobial material and used for a variety of applications due to their potent antimicrobial activities [10-14]. These materials are found to be capable of killing bacteria that are resistant to other types of cationic antibacterials [15]. The examples of QAS-containing materials as antibacterials for dental restoratives include incorporation of a methacryloyloxydodecyl pyridinium bromide (MDPB) as an antibacterial monomer into resin composites [12], use of methacryloxylethyl cetyl ammonium chloride (DMAECB) as a component for antibacterial bonding agents $[16,17]$, and incorporation of quaternary ammonium polyethyleneimine (PEI) nanoparticles into composite resins $[18,19]$. All these studies found that QAS-containing materials did exhibit significant antibacterial activities. In this study, we proposed to synthesize the novel QAScontaining oligomers for developing antibacterial dental resin composites.

The objective of this study was to synthesize new quaternary ammonium salt (QAS)-containing oligomers, incorporate them to dental resin composites, and evalu- 
ate the effects of these new oligomers on the mechanical strength and antibacterial activity of the formed composites.

\section{MATERIALS AND METHODS}

\subsection{Materials}

Bromoethane, bromohexane, bromododecane, bromohexadecane, 2-dimethylaminoethanol (DMAE), 2-hdroxyethyl methacrylate (HEMA), 1,2,4,5-benzenetetracarboxylic dianhydride (BTCDA), 3,3',4,4'-benzophenonetetracarboxylic dianhydride (BPTCDA), 4,4'-(4,4'isopropylidenediphenoxy)-bis(phthalic anhydride) (IPDPBisPA), triethylene glycol dimethacrylate (TEGDMA), bisphenol A glycerolate dimethacrylate (BisGMA), dlcamphoroquinone (CQ), 2-(dimethylamino)ethyl methacrylate (DMAEMA), pyridine, N,N'-dicyclohexylcarbodiimide (DCC), N-methylpyrrolidone (NMP) and hexane were used as received from VWR International Inc (Bristol, CT) without further purifications. The untreated glass fillers for Herculite XRV (0.7 microns) were used as received from Sybron Dental Specialties (Newport Beach, CA).

\subsection{Synthesis and Characterization}

\subsubsection{Synthesis of the Polymerizable Oligomers Bearing Quaternary Ammonium Bromide (QAB)}

The polymerizable oligomer bearing quaternary ammonium bromide (QAB) was synthesized via three steps: synthesis of the hydroxyl group-containing QAB, coupling the $\mathrm{QAB}$ onto the oligomer, and introduction of the methacrylate groups onto the oligomer. Briefly, 1) to a flask containing DMAE $(0.01 \mathrm{~mol})$ in methanol, bromododecane $(0.013 \mathrm{~mol})$ was added. The reaction was run at room temperature overnight. After most of methanol was removed, the mixture was washed with hexane 3 times. The formed 2-dimethyl-2-dodecyl-1-hydroxyethylammonium bromide (or namely B12) was purified by dissolving in methanol and washing with hexane several times before drying in a vacuum oven; 2) to a flask containing BPTCDA (0.01 mol) in NMP, B12 (0.013 mol) was added in the presence of pyridine. After the reaction was run at $60^{\circ} \mathrm{C}$ for $4 \mathrm{~h}$, the mixture was precipitated from hexane, followed by washing with hexane 3 times; $3)$ the purified product BPDQAB $(0.01 \mathrm{~mol}$, an adduct of BPTCDA and B12) in NMP was used to react with HEMA $(0.013 \mathrm{~mol})$ in the presence of DCC $(0.013 \mathrm{~mol})$ and pyridine ( $1.5 \%$ by weight of HEMA). After the reaction was run at room temperature overnight, the mixture was precipitated with hexane, followed by washing with hexane several times. The purified oligomer BPDQABDMA (an adduct of BPDQAB and HEMA) was then dried in a vacuum oven at room temperature prior to use.
The other two oligomers, BDQABDMA (an adduct of BDQAB and HEMA) and IPDPDQABDMA (an adduct of IPDPDQAB and HEMA), were synthesized the same as shown above. The structures of three starting dianhydrides, TEGDMA and BisGMA as well as the synthesis scheme are shown in Figure 1.

\subsubsection{Characterization}

The chemical structures of the synthesized oligomers were characterized by Fourier transform-infrared (FT-IR) spectroscopy and nuclear magnetic resonance (NMR) spectroscopy. The proton NMR $\left({ }^{1} \mathrm{HNMR}\right)$ spectra were obtained on a $500 \mathrm{MHz}$ Bruker NMR spectrometer (Bruker Avance II, Bruker BioSpin Corporation, Billerica, MA) using deuterated dimethyl sulfoxide and chloroform as solvents and FT-IR spectra were obtained on a FT-IR spectrometer (Mattson Research Series FT/IR 1000, Madison, WI).
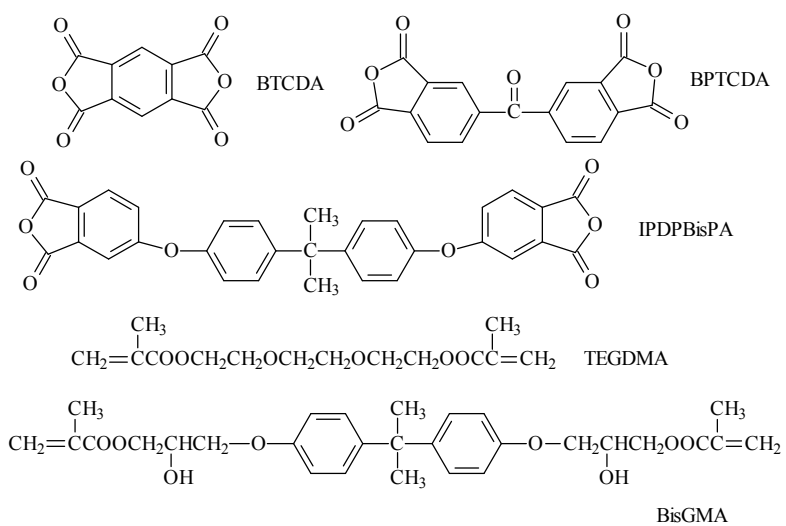

(a)

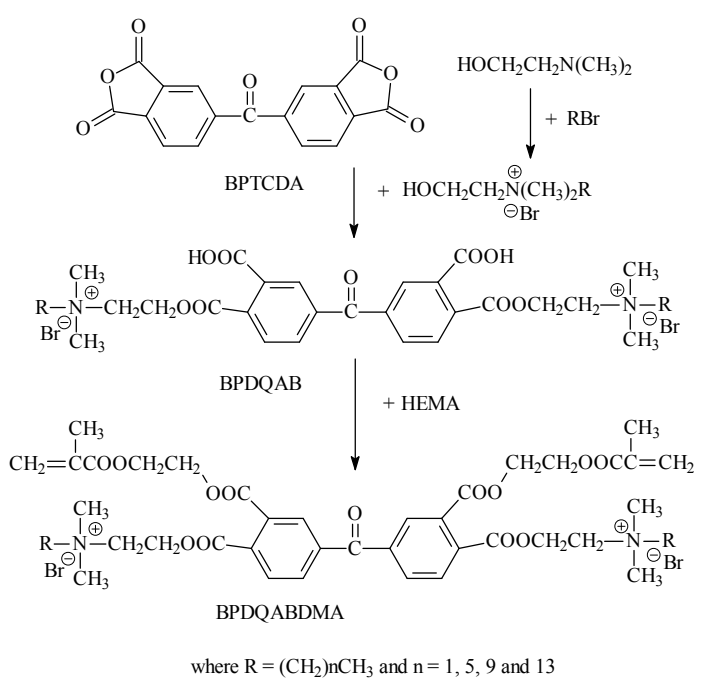

(b)

Figure 1. Structures and synthesis scheme: (a) Structures of BTCDA, BPTCDA, IPDPBisPA, TEGDMA and BisGMA; (b) Synthesis scheme for preparation of the polymerizable quaternized oligomer BPDQABDMA. 


\subsection{Evaluation}

\subsubsection{Sample Preparation for Mechanical Strength Tests}

The experimental resin composites were formulated with a two-component system (liquid and powder) [20]. The liquid was formulated with the newly synthesized oligomer, BisGMA, TEGDMA, CQ and DMAEMA. The synthesized oligomer, BisGMA and TEGDMA were mixed in a ratio of oligomer/BisGMA/TEGDMA = $30 / 35 / 35$ (oligomer $=30 \%)$ unless specified. CQ $(1.0 \%$ by weight) and DMAEMA (2.0\%) were added for photoinitiation. The untreated glass Herculite XRV (0.7 microns) powders were used as fillers and treated with $\gamma$ (trimethoxysilyl)propyl methacrylate, following the published protocol [21]. A filler level at $75 \%$ (by weight) was used throughout the study.

Specimens were fabricated by thoroughly mixing the liquid with the treated fillers at room temperature according to the published protocol [20,21]. Briefly, the cylindrical specimens were prepared in glass tubing with dimensions of $4 \mathrm{~mm}$ in diameter by $8 \mathrm{~mm}$ in length for compressive strength (CS), $4 \mathrm{~mm}$ in diameter by $2 \mathrm{~mm}$ in length for diametral tensile strength (DTS), and $4 \mathrm{~mm}$ in diameter by $2 \mathrm{~mm}$ in depth for antibacterial tests. The rectangular specimens were prepared in a split Teflon mold with dimensions of $3 \mathrm{~mm}$ in width by $3 \mathrm{~mm}$ in thickness by $25 \mathrm{~mm}$ in length for flexural strength (FS) test. All the specimens were exposed to blue light (EXAKT 520 Blue Light Polymerization Unit, EXAKT Technologies, Inc., Oklahoma City, OK) for $2 \mathrm{~min}$, followed by removing from the mold or conditioned in distilled water at $37^{\circ} \mathrm{C}$ for $24 \mathrm{~h}$ prior to testing, unless specified.

\subsubsection{Strength Measurements}

CS, DTS and FS tests were performed on a screw-driven mechanical tester (QTest QT/10, MTS Systems Corp., Eden Prairie, MN), with a crosshead speed of $1 \mathrm{~mm} / \mathrm{min}$. The FS test was performed in three-point bending with a span of $20 \mathrm{~mm}$ between supports. Six to eight specimens were tested to obtain a mean value for each material or formulation in each test. CS was calculated using an equation of $\mathrm{CS}=\mathrm{P} / \pi \mathrm{r}^{2}$, where $\mathrm{P}=$ the load at fracture and $\mathrm{r}=$ the radius of the cylinder. DTS was determined from the relationship DTS $=2 \mathrm{P} / \pi \mathrm{dt}$, where $\mathrm{P}=$ the load at fracture, $d=$ the diameter of the cylinder, and $t=$ the thickness of the cylinder. FS was obtained using the expression $\mathrm{FS}=3 \mathrm{Pl} / 2 \mathrm{bd}^{2}$, where $\mathrm{P}=$ the load at fracture, 1 $=$ the distance between the two supports, $\mathrm{b}=$ the breadth of the specimen, and $\mathrm{d}=$ the depth of the specimen.

\subsubsection{MIC Test for the Synthesized QAB}

The minimal inhibitory concentration or MIC of the synthesized QAB was determined following the pub- lished protocol with a slight modification [22]. Briefly, colonies of S. mutans (UA159) were suspended in $5 \mathrm{ml}$ of Tryptic soy Broth (TSB) prior to MIC testing. Twofold serial dilutions of the synthesized QAB were prepared in TSB, followed by placing in 96-well flat-bottom microtiter plates with a volume of $250 \mu \mathrm{l}$ per well. The final concentration of the $\mathrm{QAB}$ ranged from 1.563 to $2 \times$ $10^{4} \mu \mathrm{g} / \mathrm{ml}$. The microtiter plate was then inoculated with S. mutans suspension (cell concentration $=5 \times 10^{5}$ $\mathrm{CFU} / \mathrm{ml}$ ) and incubated at $37^{\circ} \mathrm{C}$ for $48 \mathrm{~h}$ prior to $\mathrm{MIC}$ testing. The absorbance was measured at $595 \mathrm{~nm}$ via a microplate reader (SpectraMax 190, Molecular Devices, CA) to assess the cell growth. Chloehexidine (CHX) and dimethylsulfoxide were used as positive and negative controls, respectively. Triple replica was used to obtain a mean value for each QAB.

\subsubsection{Antibacterial Test for the Formed Cements}

The antibacterial test was conducted following the published procedures [23]. S. mutans was used for evaluation of antibacterial activity of the studied cements. Briefly, colonies of S. mutans (UA159) were suspended in $5 \mathrm{ml}$ of Tryptic soy Broth (TSB), supplemented with $1 \%$ sucrose, to make a suspension with $10^{8} \mathrm{CFU} / \mathrm{ml}$ of $\mathrm{S}$. mutans, after $24 \mathrm{~h}$ incubation. Specimens pretreated with ethanol $(10 \mathrm{sec})$ were incubated with S. mutans in TSB at $37^{\circ} \mathrm{C}$ for $48 \mathrm{~h}$ under anaerobic condition with $5 \% \mathrm{CO}_{2}$. After equal volumes of the red and the green dyes (LIVE/DEAD BacLight bacterial viability kit L7007, Molecular Probes, Inc., Eugene, OR, USA) were combined in a microfuge tube and mixed thoroughly for 1 min, $3 \mu \mathrm{l}$ of the dye mixture was added to $1 \mathrm{ml}$ of the bacteria suspension, mixed by vortexing for $10 \mathrm{sec}$, sonicating for $10 \mathrm{sec}$ as well as vortexing for another 10 $\mathrm{sec}$, and kept in dark for about $15 \mathrm{~min}$, prior to analysis. Then $20 \mu \mathrm{l}$ of the stained bacterial suspension was analyzed using a fluorescent microscope (Nikon MicrophotFXA, Melville, NY, USA). Triple replica was used to obtain a mean value for each material.

\subsubsection{Statistical Analysis}

One-way analysis of variance (ANOVA) with the post hoc Tukey-Kramer multiple-range test was used to determine significant differences of mechanical strength and antibacterial tests among the materials in each group. A level of $\alpha=0.05$ was used for statistical significance.

\section{RESULTS}

\subsection{Characterization}

The characteristic peaks $\left(\mathrm{cm}^{-1}\right)$ from the FT-IR spectra shown in Figure 2 for DMAE, bromododecane, B12, BPTCDA and BPDQAB (an adduct of BPTCDA and B12) are listed in Table 1. The appearance of both peaks at 3600-3200 and 1632 for $=\mathrm{N}^{+}=$groups 


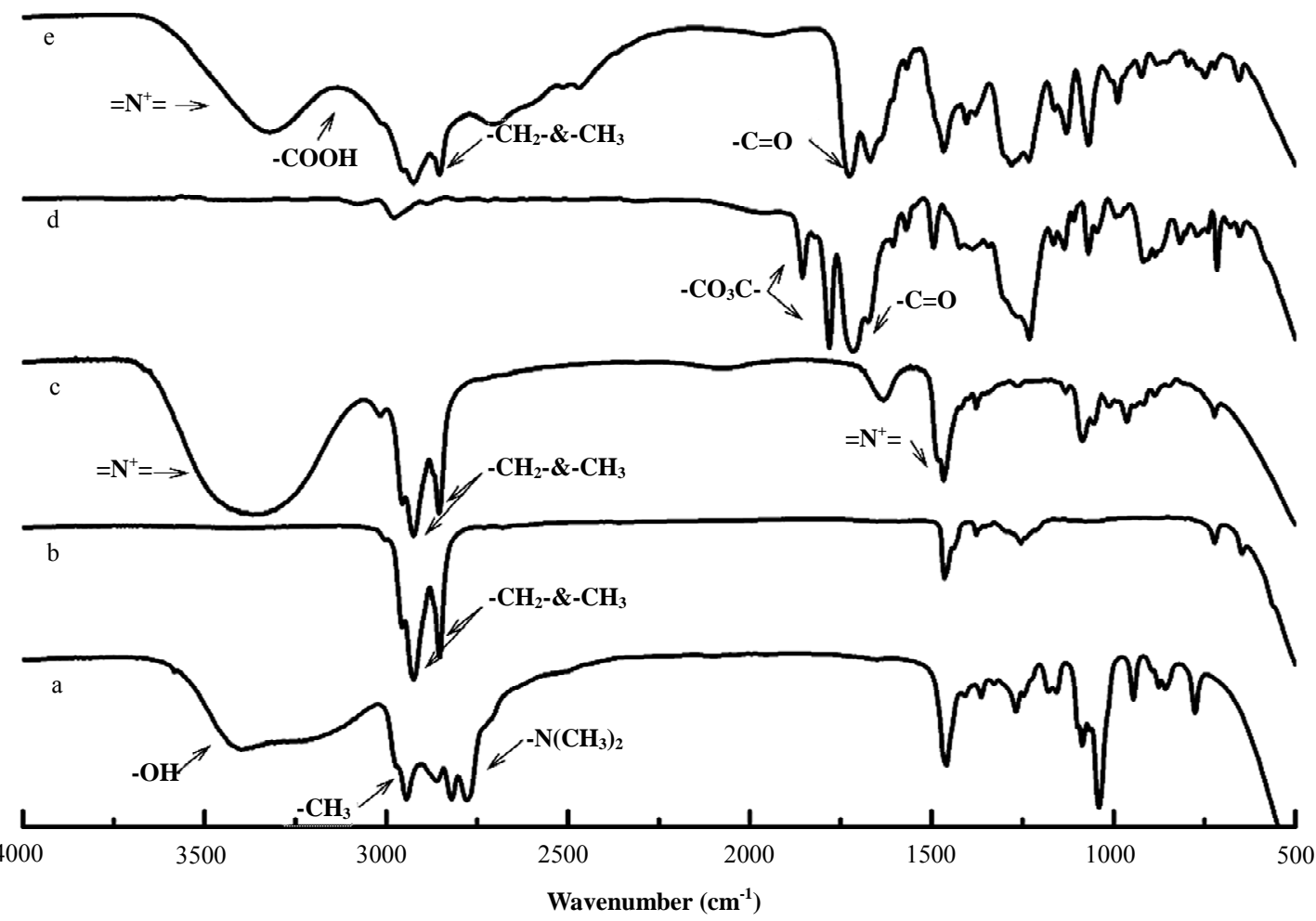

Figure 2. FT-IR spectra for DMAE, bromododecane, B12, BPTCDA and BPDQAB (an adduct of BPTCDA and B12): (a) DMAE; (b) bromododecane; (c) B12; (d) BPTCDA and (e) BPDQAB.

Table 1. The characteristic peaks from the FT-IR spectra shown in Figure 2.

\begin{tabular}{|c|c|}
\hline Material & The characteristic peaks $\left(\mathrm{cm}^{-1}\right)$ \\
\hline DMAE & $\begin{array}{l}3399(\mathrm{O}-\mathrm{H} \text { stretching }), 2944\left(\mathrm{C}-\mathrm{H} \text { stretching on }-\mathrm{CH}_{2}-\right), 2861\left(\mathrm{C}-\mathrm{H} \text { stretching on }-\mathrm{CH}_{3}\right), 2820 \text { and } 2779(\mathrm{C}-\mathrm{H} \\
\left.\text { stretching on }-\mathrm{N}\left(\mathrm{CH}_{3}\right)_{2}\right), 1459,1364 \text { and } 1268\left(\mathrm{C}-\mathrm{H} \text { deformation on }-\mathrm{CH}_{2}-\right), 1090(\mathrm{O}-\mathrm{H} \text { deformation }) \text {, and } 1040 \\
\text { as well as } 776(\mathrm{C}-\mathrm{N} \text { deformation })\end{array}$ \\
\hline $\begin{array}{l}\text { Bromo- } \\
\text { dodecane }\end{array}$ & $\begin{array}{l}2924\left(\mathrm{C}-\mathrm{H} \text { stretching on }-\mathrm{CH}_{2}-\right), 2854\left(\mathrm{C}-\mathrm{H} \text { stretching on }-\mathrm{CH}_{3}\right), 1465,1377 \text { and } 1255(\mathrm{C}-\mathrm{H} \text { deformation on } \\
\left.-\mathrm{CH}_{2-}\right) \text {, and } 722 \text { as well as } 647(\mathrm{C}-\mathrm{Br} \text { deformation) }\end{array}$ \\
\hline B12 & $\begin{array}{l}3600-3200\left(=\mathrm{N}^{+}=\text {stretching }\right), 2917\left(\mathrm{C}-\mathrm{H} \text { stretching on }-\mathrm{CH}_{2}^{-}\right), 2850\left(\mathrm{C}-\mathrm{H} \text { stretching on }-\mathrm{CH}_{3}\right), 1632\left(=\mathrm{N}^{+}=\right. \\
\text {deformation }), 1470\left(\mathrm{C}-\mathrm{H} \text { deformation on }-\mathrm{CH}_{2^{-}}\right) \text {, and } 1090 \text { as well as } 730(\mathrm{O}-\mathrm{H} \text { deformation })\end{array}$ \\
\hline BPTCDA & $\begin{array}{l}2910(=\mathrm{C}-\mathrm{H} \text { stretching on phenyl groups), } 1855 \text { and } 1782 \text { (two }-\mathrm{C}=\mathrm{O} \text { stretching on five-membered ring acid } \\
\text { anhydride), } 1717(-\mathrm{C}=\mathrm{O} \text { stretching on ketone), } 1610 \text { and } 1570(-\mathrm{C}=\mathrm{C} \text { - stretching on phenyl groups), } 1495(-\mathrm{C}=\mathrm{O} \\
\text { deformation vibration), } 1231 \text { (other vibrations on five-membered ring acid anhydrides), and } 1388,1135,1069 \text {, } \\
917,715 \text { and } 625 \text { (-C=C-and }-=\mathrm{C}-\mathrm{H} \text { stretching, out-of-plane and other vibrations on phenyl groups) }\end{array}$ \\
\hline $\begin{array}{l}\text { BPDQA } \\
\text { B }\end{array}$ & $\begin{array}{l}3320\left(=\mathrm{N}^{+}=\text {stretching }\right), 3600-2600(\mathrm{O}-\mathrm{H} \text { stretching on }-\mathrm{COOH}), 2924\left(\mathrm{C}-\mathrm{H} \text { stretching on }-\mathrm{CH}_{2}-\right), 2854(\mathrm{C}-\mathrm{H} \\
\left.\text { stretching on }-\mathrm{CH}_{3}\right), 1726 \text { and } 1669(-\mathrm{C}=\mathrm{O} \text { stretching on esters }), 1587(-\mathrm{C}=\mathrm{O} \text { stretching on ketone }), 1467(-\mathrm{C}=\mathrm{O} \\
\text { deformation vibration), and } 1388,1135,1069,917,715 \text { and } 625(-\mathrm{C}=\mathrm{C} \text {-and }-=\mathrm{C}-\mathrm{H} \text { stretching, out-of-plane and } \\
\text { other vibrations on phenyl groups })\end{array}$ \\
\hline
\end{tabular}

and disappearance of the peaks at 1040 and 776 for C-N groups confirmed the formation of B12. The disappearance of the peaks at 1855 and 1782 for anhydrides as well as appearance of a broad peak at $3600-2600$ for $-\mathrm{COOH}$, a relatively sharp peak at 3320 for $=\mathrm{N}^{+}=$and strong peaks at 2924 and 2854 for $-\mathrm{CH}_{3}$ and $-\mathrm{CH}_{2}$ groups confirmed the formation of BPDQAB.

The characteristic peaks $\left(\mathrm{cm}^{-1}\right)$ from the FT-IR spectra shown in Figure 3 for HEMA, BPDQAB, BPDQABDMA, BDQABDMA and IPDPDQABDMA are listed in Table 2. The disappearance of the peak at $3428(-\mathrm{OH}$ from HEMA) as well as appearance of the peaks at 


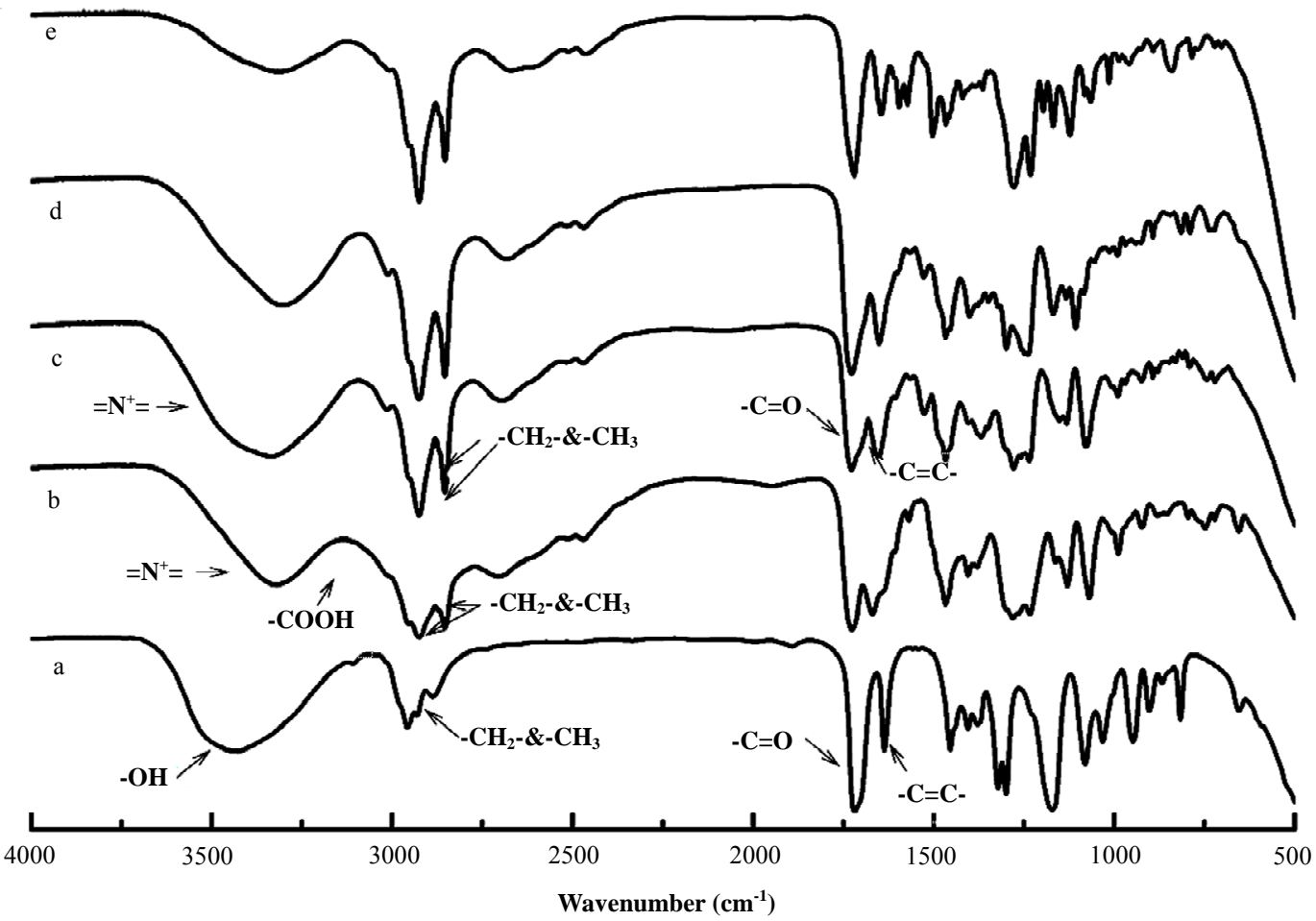

Figure 3. FT-IR spectra for HEMA, BPDQAB, BPDQABDMA (an adduct of BPDQAB and HEMA), BDQABDMA (an adduct of BDQAB and HEMA) and IPDPDQABDMA (an adduct of IPDPDQAB and HEMA): (a) HEMA; (b) BPDQAB; (c) BPDQABDMA; (d) BDQABDMA and (e) IPDPDQABDMA.

Table 2. The characteristic peaks from the FT-IR spectra shown in Figure 3.

\begin{tabular}{|c|c|}
\hline Material & The characteristic peaks $\left(\mathrm{cm}^{-1}\right)$ \\
\hline HEMA & $\begin{array}{l}3428(\mathrm{O}-\mathrm{H} \text { stretching }), 2957\left(\mathrm{C}-\mathrm{H} \text { stretching on }-\mathrm{CH}_{2}-\right), 2889\left(\mathrm{C}-\mathrm{H} \text { stretching on }-\mathrm{CH}_{3}\right), 1719(-\mathrm{C}=\mathrm{O} \\
\text { stretching on ester }) \text {, and } 1637(-\mathrm{C}=\mathrm{C} \text { stretching })\end{array}$ \\
\hline BPDQAB & $\begin{array}{l}3320\left(=\mathrm{N}^{+}=\text {stretching }\right), 3600-2600(\mathrm{O}-\mathrm{H} \text { stretching on }-\mathrm{COOH}), 2924\left(\mathrm{C}-\mathrm{H} \text { stretching on }-\mathrm{CH}_{2}-\right) \text {, } \\
2854\left(\mathrm{C}-\mathrm{H} \text { stretching on }-\mathrm{CH}_{3}\right), 1726 \text { and } 1669(-\mathrm{C}=\mathrm{O} \text { stretching on esters }), 1587(-\mathrm{C}=\mathrm{O} \text { stretching on } \\
\text { ketone }), 1467(-\mathrm{C}=\mathrm{O} \text { deformation vibration }) \text {, and } 1388,1135,1069,917,715 \text { and } 625(-\mathrm{C}=\mathrm{C}-\text { and } \\
-=\mathrm{C}-\mathrm{H} \text { stretching, out-of-plane and other vibrations on phenyl groups })\end{array}$ \\
\hline BPDQABDMA & $\begin{array}{l}3328\left(=\mathrm{N}^{+}=\text {stretching }\right), 2924\left(\mathrm{C}-\mathrm{H} \text { stretching on }-\mathrm{CH}_{2}-\right), 2854\left(\mathrm{C}-\mathrm{H} \text { stretching on }-\mathrm{CH}_{3}\right), 1726(-\mathrm{C}=\mathrm{O} \\
\text { stretching on esters }), 1647(\mathrm{C}=\mathrm{C} \text { stretching on methacrylates }), 1587(-\mathrm{C}=\mathrm{O} \text { stretching on ketone }), 1467 \\
(-\mathrm{C}=\mathrm{O} \text { deformation vibration }) \text {, and } 1388,1135,1069,917,715 \text { and } 625(-\mathrm{C}=\mathrm{C} \text {-and }-=\mathrm{C}-\mathrm{H} \text { stretching, } \\
\text { out-of-plane and other vibrations on phenyl groups })\end{array}$ \\
\hline BDQABDMA & Similar to BPDQABDMA \\
\hline IPDPDQABDMA & Similar to both BPDQABDMA and BDQABDMA. \\
\hline
\end{tabular}

3600-3200 for $=\mathrm{N}^{+}=, 2923$ and 2853 for $-\mathrm{CH}_{2^{-}}$and $-\mathrm{CH}_{3}$ and 1647 for $\mathrm{C}=\mathrm{C}$ groups confirmed the formation of three polymerizable quaternized oligomers.

The characteristic chemical shifts (ppm) from the ${ }^{1}$ HNMR spectra shown in Figure 4 for DMEA, bromododecane, B12, BPTCDA and BPDQABDMA are listed in Table 3. The appearance of all the new peaks in the spectrum, especially at 5.82 and 6.25 for carbon-carbon double bond and 7.82-8.40 for phenyl groups confirmed the successful attachment of HEMA and B12 onto the BPTCDA.

\subsection{Evaluation}

Table 4 shows the code, description and MIC of the 

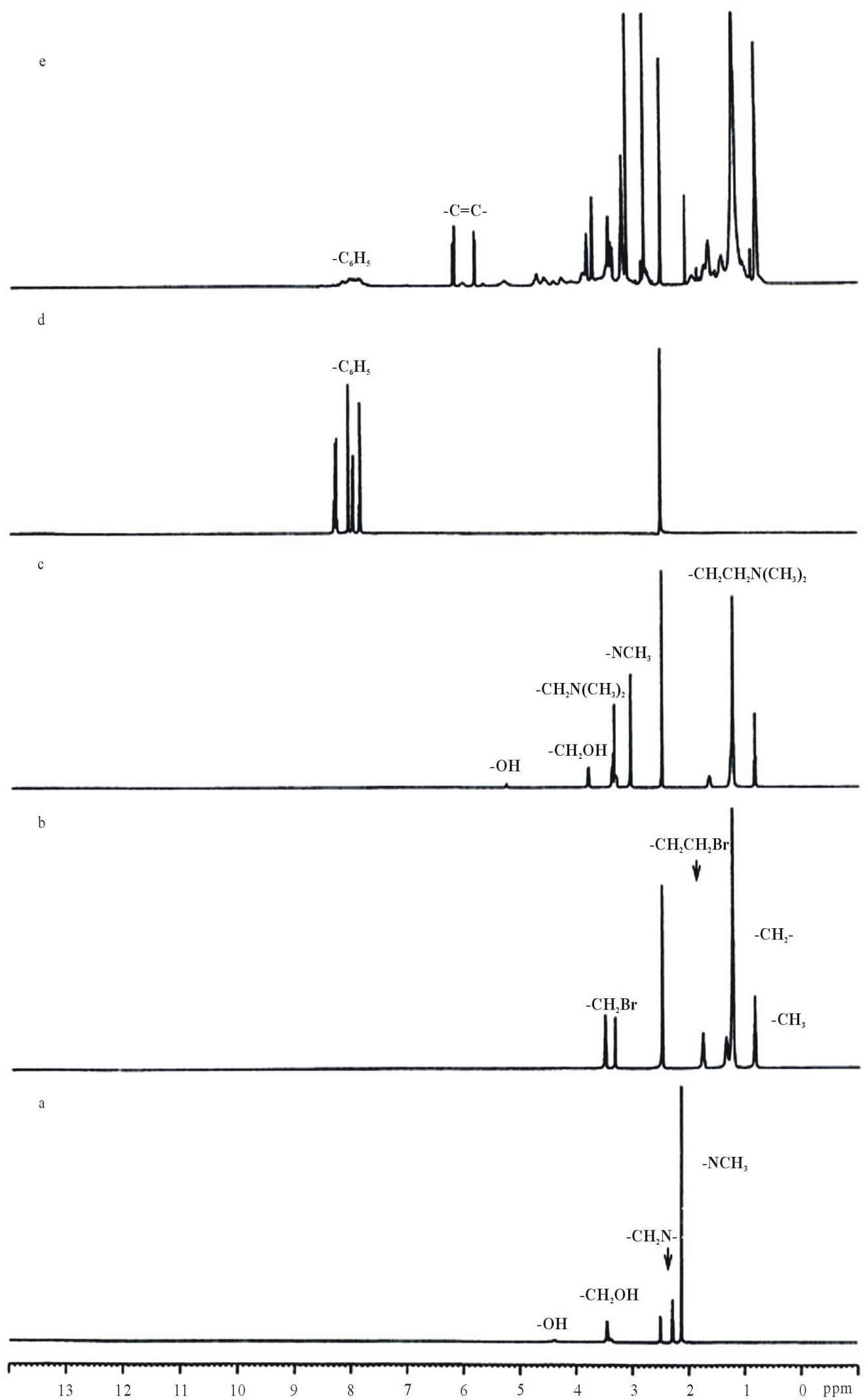

Figure 4. ${ }^{1} \mathrm{HNMR}$ spectra for DMAE, bromododecane, B12, BPTCDA and BPDQABDMA: (a) DMAE; (b) bromododecane; (c) B12; (d) BPTCDA and (e) BPDQABDMA. 
Table 3. The characteristic chemical shifts from the ${ }^{1} \mathrm{HNMR}$ spectra shown in Figure 4.

\begin{tabular}{ll}
\hline Material & The characteristic chemical shifts $(\mathrm{ppm})$ \\
\hline DMEA & $4.40(-\mathrm{OH}), 3.42\left(-\mathrm{CH}_{2} \mathrm{OH}\right), 2.30\left(-\mathrm{CH}_{2} \mathrm{~N}-\right)$ and $2.10\left(\mathrm{H}_{3} \mathrm{CN}-\right)$ \\
Bromododecane & $3.51\left(-\mathrm{CH}_{2} \mathrm{Br}\right), 1.80\left(-\mathrm{CH}_{2} \mathrm{CH}_{2} \mathrm{Br}\right), 1.38\left(-\mathrm{CH}_{2}-\right.$, all $)$ and $0.89\left(-\mathrm{CH}_{3}\right)$ \\
B12 & $\begin{array}{l}5.25(-\mathrm{OH}), 3.82\left(-\mathrm{CH}_{2} \mathrm{OH}\right), 3.40\left(-\mathrm{CH}_{2} \mathrm{~N}\left(\mathrm{CH}_{3}\right)_{2}\right), 3.08\left(\mathrm{H}_{3} \mathrm{CN}-\right), 1.55 \\
\left(-\mathrm{CH}_{2} \mathrm{CH}_{2} \mathrm{~N}\left(\mathrm{CH}_{3}\right)_{2}\right), 1.25\left(-\mathrm{CH}_{2}-\text { all }\right) \text { and } 0.89\left(-\mathrm{CH}_{3}\right)\end{array}$ \\
BPTCDA & $7.85-8.40(-\mathrm{H}$, all from the phenyl groups $)$ and $2.50(\mathrm{TMS})$ \\
BPDQABDMA & $\begin{array}{l}7.85-8.40(-\mathrm{H}, \text { all from the phenyl groups }), 5.82 \text { and } 6.25(=\mathrm{C}-, \text { from methacrylates }) \text { and all the other chemical shifts } \\
\text { similar to those shown on B12 }\end{array}$ \\
\hline
\end{tabular}

Table 4. Codes, description, MIC values of the synthesized QAB.

\begin{tabular}{clcc}
\hline Code & \multicolumn{1}{c}{$\mathrm{QAB}^{1}$} & Chain length & $\mathrm{MIC}(\mu \mathrm{g} / \mathrm{ml})^{2}$ \\
\hline B2 & 2-Dimethyl-2-ethyl-1-hydroxyethylammonium bromide & 2 & 20,000 \\
B6 & 2-Dimethyl-2-hexyl-1-hydroxyethylammonium bromide & 6 & 1,000 \\
B12 & 2-Dimethyl-2-dodecyl-1-hydroxyethylammonium bromide & 12 & 25 \\
B16 & 2-Dimethyl-2-hexadecyl-1-hydroxyethylammonium bromide & 16 & 1.563 \\
\hline
\end{tabular}

synthesized QAB. The MIC values ranged from 1.563 to $2 \times 10^{4} \mu \mathrm{g} / \mathrm{ml}$ for B16 to B2.

Figure 5 shows the effect of the substitute chain length on the synthesized oligomers on CS and S. mutans viability of the experimental resin composite. The mean $\mathrm{CS}$ value (MPa) was in the decreasing order of $\mathrm{B} 2$ $>\mathrm{B} 6>\mathrm{B} 12>\mathrm{B} 16$, where there were no statistically significant differences between $\mathrm{B} 2$ and $\mathrm{B} 6$, between $\mathrm{B} 6$ and $\mathrm{B} 12$, and between $\mathrm{B} 12$ and $\mathrm{B} 16(\mathrm{p}>0.05)$. Increasing the substitute chain length on the oligomer decreased the CS values of the resin composite. The mean S. mutans viability was in the decreasing order of $\mathrm{B} 2>\mathrm{B} 6>$ $\mathrm{B} 12>\mathrm{B} 16$, where all the resin composites were signifycantly different from each other $(\mathrm{p}<0.05)$.

Figure 6 shows the effect of different oligomers on CS and S. mutans viability of the resin composite. The mean $\mathrm{CS}$ value (MPa) of the dry resin composite was in the decreasing order of $\mathrm{A}>\mathrm{B}>\mathrm{C}>\mathrm{D}$, where there were no statistically significant differences among $\mathrm{B}, \mathrm{C}$ and $\mathrm{D}$ $(p>0.05)$. The mean CS value (MPa) of the wet resin composite (the composite after conditioning in distilled water for $24 \mathrm{~h}$ ) was in the decreasing order of $\mathrm{A}>\mathrm{D}>\mathrm{C}$ $>\mathrm{B}$, where there were no statistically significant differences among $B, C$ and $D(p>0.05)$. The mean S. mutans viability was in the decreasing order of $\mathrm{A}>\mathrm{D}>\mathrm{C}>\mathrm{B}$, where there were no statistically significant differences between $B$ and $C$ and between $C$ and $D(p>0.05)$.

Figure 7 shows the effect of the oligomer loading on
$\mathrm{CS}$ and S. mutans viability. Both mean $\mathrm{CS}$ value (MPa) and S. mutans viability were in the decreasing order of $10 \%>20 \%>30 \%>50 \%>70 \%$, where all the resin composites were significantly different from each other in either category $(\mathrm{p}<0.05)$.

Figure 8 shows the effect of aging of both unmodified and QAB-modified resin composites on CS and S. mutans viability. The mean $\mathrm{CS}$ value $(\mathrm{MPa})$ was in the decreasing order: (A) Unmodified composite: $1 \mathrm{~d}>7 \mathrm{~d}>$ $30 \mathrm{~d}$, where there were no statistically significant differences between $1 \mathrm{~d}$ and $7 \mathrm{~d}(\mathrm{p}>0.05)$; (B) QAB-modified composite: $1 \mathrm{~d}>7 \mathrm{~d}>30 \mathrm{~d}$, where all were significantly different from each other $(\mathrm{p}<0.05)$. The mean $\mathrm{S}$. mutans viability values were statistically the same within 30 days for either unmodified or QAB-modified composite $(\mathrm{p}<0.05)$.

Table 5 shows the property comparison of the unmodified and modified resin composites. These properties include yield strength (YS), compressive modulus (M), CS, diametral tensile strength (DTS), flexural strength (FS) and antibacterial activity.

\section{DISCUSSION}

Currently there is a growing interest in preventing or reducing biofilm formation in many biomedical areas. In preventive restorative dentistry, secondary caries is a critical issue and prevention of secondary caries plays a key role in long-lasting restorations [1-4]. Secondary caries is found to be the main reason to the restoration 


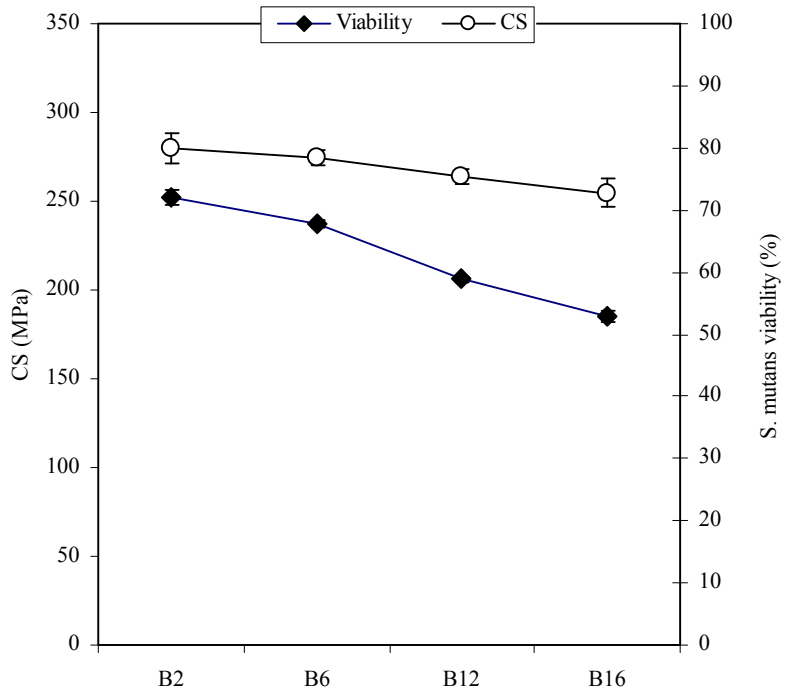

Figure 5. Effect of the substitute chain length on the synthesized $\mathrm{QAB}$ on $\mathrm{CS}$ and S. mutans viability of the resin compiosite: B2, B6, B12 and B16 represent the substitute chain length on the synthesized $\mathrm{QAB}$ (see codes and description in Table 1). The composite was composed of BPDQABDMA/BisGMA/TEGDMA at a ratio of 20:40:40 (by weight or BPDQABDMA $=20 \%$ ). Specimens were tested directly for CS and incubated with $\mathrm{S}$. mutans for $48 \mathrm{~h}$ for antibacterial testing.

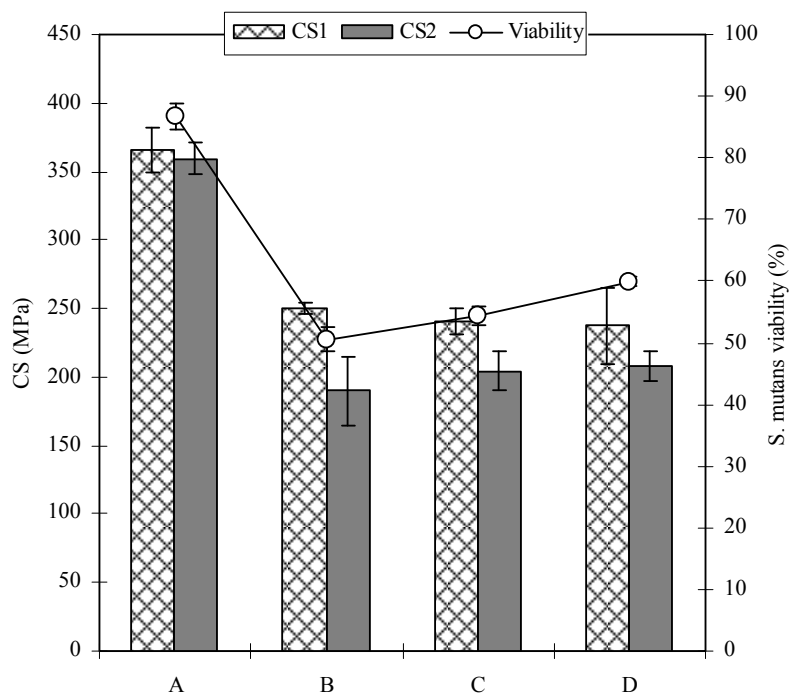

Figure 6. Comparison among the resin composites having different QAB-containing oligomers via $\mathrm{CS}$ and S. mutans viability testing: $\mathrm{A}, \mathrm{B}, \mathrm{C}$ and $\mathrm{D}$ stand for the resin composites composed of BisGMA/TEGDMA $=50 / 50$ (by weight), BDQABDMA/BisGMA/TEGDMA = 30/35/35, BPDQABDMA/BisGMA/TEGDMA $=30 / 35 / 35$ and IPDPDQABDMA/BisGMA/ TEGDMA $=30 / 35 / 35$, respectively. CS1 and CS2 represent the $\mathrm{CS}$ for day and wet resin composites. $\mathrm{QAB}=\mathrm{B} 12$. Specimens were tested directly for CS and incubated with $\mathrm{S}$. mutans for $48 \mathrm{~h}$ for antibacterial testing.

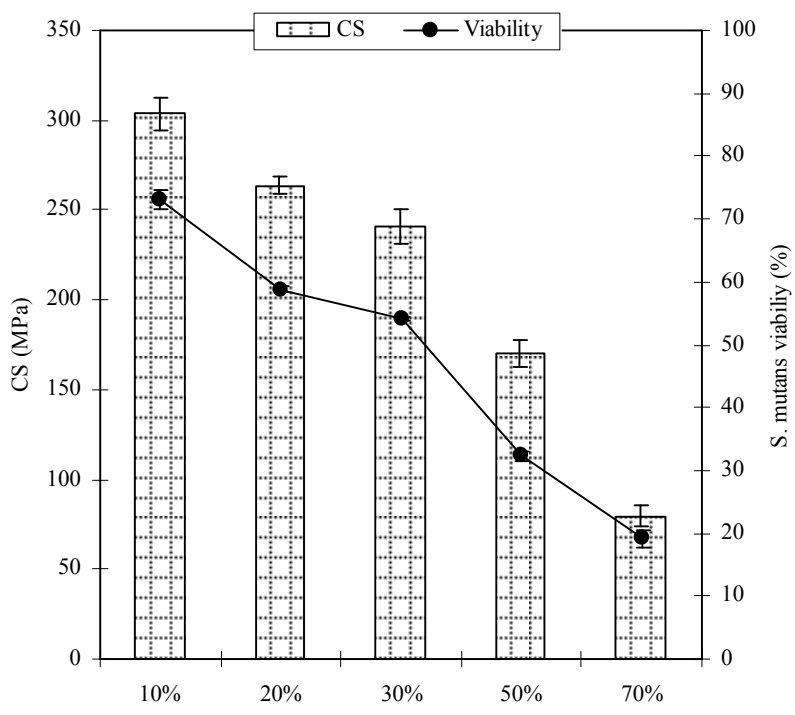

Figure 7. Effect of the QAB loading on CS and S. mutans viability: $\mathrm{BPDQABDMA}=10,20,30,50$ and $70 \%$, where BisGMA/TEGDMA $=50 / 50 . \mathrm{QAB}=\mathrm{B} 12$. Specimens were tested directly for $\mathrm{CS}$ and incubated with $\mathrm{S}$. mutans for $48 \mathrm{~h}$ for antibacterial testing.

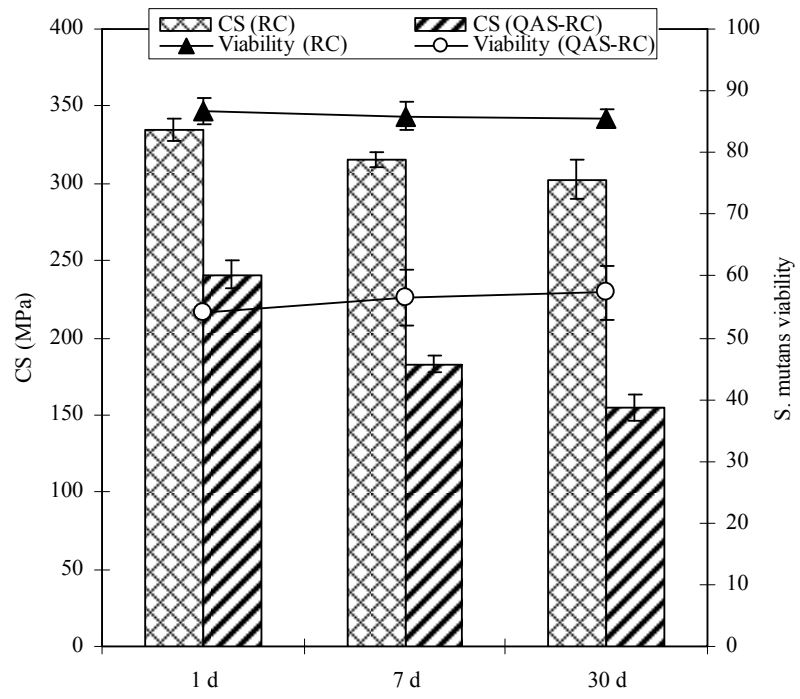

Figure 8. Effect of aging on $\mathrm{CS}$ and $\mathrm{S}$. mutans viability: BPDQABDMA $=30 \%$; BisGMA/TEGDMA $=50 / 50 ; \mathrm{QAB}=$ $\mathrm{B} 12$. The specimens were conditioned in distilled water for 1 day, 7 days and 30 days, followed by direct testing for CS and incubating with S. mutans for $48 \mathrm{~h}$ for antibacterial testing.

failure of dental restoratives [1-4]. Secondary caries that often occurs at the interface between the restoration and the cavity preparation is mainly caused by demineralization of tooth structure due to invasion of plaque bacteria (acid-producing bacteria) such as S. mutans in the presence of fermentable carbohydrates [4]. Therefore, preventing these bacteria from invasion to natural tooth is 
Table 5. Comparison of properties of the unmodified and modified resin composites.

\begin{tabular}{lcccccc}
\hline Material $^{1}$ & $\mathrm{YS}^{2}[\mathrm{MPa}]$ & $\mathrm{M}^{3}[\mathrm{GPa}]$ & $\mathrm{UCS}^{4}[\mathrm{MPa}]$ & $\mathrm{DTS}^{5}[\mathrm{MPa}]$ & FS & Viability (\%) \\
\hline RC & $155.8(11)^{\mathrm{a}, 6}$ & $7.16(0.33)^{\mathrm{b}}$ & $365.5(15)^{\mathrm{c}}$ & $63.7(1.6)^{\mathrm{d}}$ & $114.6(8.7)$ & $86.8(2.2)$ \\
RC (24h) & $153.7(6.2)^{\mathrm{a}}$ & $7.09(0.15)^{\mathrm{b}}$ & $359.5(12)^{\mathrm{c}}$ & $64.7(2.7)^{\mathrm{d}}$ & $112.8(10)$ & \\
QAB-RC & $125.1(5.2)$ & $6.19(0.06)$ & $240.9(9.2)$ & $45.5(2.8)$ & $83.5(5.6)$ & $54.3(1.5)$ \\
QAB-RC (24h) & $69.1(3.6)$ & $3.82(0.07)$ & $204.4(14)$ & $34.4(4.7)$ & $70.6(8.5)^{\mathrm{c}}$ & \\
\hline
\end{tabular}

${ }^{1} \mathrm{RC}$ and QAB-RC stand for the day specimens of unmodified and QAB-modified resin composites, whereas RC (24h) and QAB-RC (24h) represent the wet specimens after conditioning in distilled water at $37{ }^{\circ} \mathrm{C}$ for $24 \mathrm{~h} ;{ }^{2} \mathrm{YS}=\mathrm{CS}$ at yield; ${ }^{3} \mathrm{M}=$ compressive modulus; ${ }^{4} \mathrm{UCS}=$ ultimate $\mathrm{CS} ;{ }^{5} \mathrm{DTS}=$ diametral tensile strength; ${ }^{6}$ Entries are mean values with standard deviations in parentheses and the mean values with the same superscript letter were not significantly different $(\mathrm{p}>0.05)$. Specimens for bacterial viability test were directly tested after incubating with S. mutans for $48 \mathrm{~h}$.

the key to long-lasting dental restorations when the microleakage or materials failure occurs at the interface. Quaternary ammonium salts (QAS) and their constructed materials represent a new trend of antimicrobial agents in biomedical applications $[10,13]$. QAS can be incurporated in many ways, including mixing with fillers, copolymerizing with other monomers and grafting onto the polymer skeletons [10-14]. The advantage of using QAS is that they can kill the microorganisms by simple contact. The mechanism of QAS to kill bacteria is believed to disrupt the surface membrane of bacteria by changing membrane permeability or surface electrostatic balance $[11,18]$. In this regard, we purposely synthesized the new QAB-containing oligomers, incorporated them into the resin composite and evaluated the CS and antibacterial activity of the formed composite.

It has been noticed that chain length on QAS has a significant effect on its antibacterial activity $[11,14]$. Generally speaking, there are four main processes for QAS to kill bacteria and they are 1) adsorption onto the negatively charged bacterial cell surface; 2) penetrating through the cell wall; 3) binding to the cytoplasmic membrane; and 4) disrupting the cytoplasmic membrane [14]. It has also been found that both positive charge density and substitute chain length are the key to the biocidal ability, because the high positive charge density may enhance the driving force and the long substitute chain may strongly interact with the cytoplasmic membranes [14]. From Table 1, it is apparent that increasing the substitute chain length significantly increased the biocidal activity of the synthesized QAB. The QAB with 16-carbon substitute chain (B16) was the highest in MIC whereas the one with 2-carbon chain (B2) was the lowest. In fact, the trend for the biocidal activity of the QAB in this study was similar to those described elsewhere $[11,14]$, i.e., the longer the substitute chain, the higher the biocidal activity. The same trend was also observed for the resin composites having the QAB-containing oligomers with different chain length. As shown in Figure 5 , increasing the substitute chain length significantly decreased the S. mutans viability. However, the CS value was also decreased. The decrease in $\mathrm{CS}$ can be attributed to the fact that simply introducing the hydrocarbon $\mathrm{CH}_{2}$ unit that does not contain any strong primary bonds such as $\mathrm{C}=\mathrm{C}$ bond or secondary bonds such as dipole-dipole or hydrogen bond could reduce mechanical strengths [24].

From the results in Figure 6, it is evident that introduction of the QAB significantly increased the antibacterial activity (or decreased the $\mathrm{S}$. mutans viability) of the resin composite. As compared to the unmodified composite A, the QAB-modified B, C and D signifycantly killed the $\mathrm{S}$. mutans from 31 to $42 \%$. Meanwhile, their CS values were also significantly decreased with a reduction of $34-36 \%$ for dry composites and $35-47 \%$ for wet composites. The significant decrease in strength for the dry composite can be attributed to the introduction of the QAB. The QAB synthesized in this study is nothing but a quaternized salt with a long-chain hydrocarbon attached, which does not contribute any strength enhancement but rather reduces the amount of $\mathrm{C}=\mathrm{C}$ instead [24]. That is why a significant decrease in CS has been observed. Regarding the dry and wet composites, the unmodified composite A behaved very differently from the QAB-modified B, C and D. No change in CS was found for the composite A after $24 \mathrm{~h}$ in water. On the other hand, statistically significant differences were found between the dry and wet composites for either B, or $\mathrm{C}$ or D. This significant decrease in CS can be attributed to the hydrophilic nature of the QAB-modified composite. The QAB by nature is a quaternary ammonium salt (QAS) bearing both positive and negative charges, which absorb water [25]. Since water serves as a plasticizer in the material [26], the QAS-containing material behaves like a hygrogel more or less [27]. No wonder the QAB-modified composites in this study showed decreased CS values after conditioning in water. Furthermore, the wet composite B seems to show more decrease in CS than either wet C or wet D, which may be attributed to the fact that $\mathrm{B}$ contains more $\mathrm{QAB}$ in 
one mole due to its lower molecular weight.

The effect of the oligomer loading on CS and antibacterial activity is shown in Figure 7. Apparently, the more the QAB-containing oligomer added the lower the CS value and the higher the antibacterial activity. With the oligomer increasing from 10 to $70 \%$, the CS value and S. mutans viability were decreased from 17 to $78 \%$ and 16 to $78 \%$, respectively. To keep the CS value close to 250 $\mathrm{MPa}$ and S. mutans viability close $50 \%$, we chose the formulation with $30 \%$ of the QAB-containing oligomer to study the aging of the modified composite. We tested the CS and S. mutans viability of both unmodified and modified composites after conditioning in distilled water for 1 day, 7 days and 30 days. As shown in Figure 8, there was nearly no change in S. mutans viability for either unmodified or modified composites, suggesting that there might be no leachable from the modified composite. On the other hand, however, a dramatic decrease in CS (MPa) was observed for the modified composite with the results of 241 for 1 day, 183 for 7 days and 155 for 30 days. In contrast, statistically significant difference was found only between 1 day (335 MPa) and 30 days $(302 \mathrm{MPa})$ for the unmodified composite. It is known that dental resin composites show a certain degree of degradation due to water sorption caused by two hydroxyl groups pendent on BisGMA and three $-\mathrm{CH}_{2} \mathrm{CH}_{2} \mathrm{O}$ units on TEGDMA (see structures in Figure 1(a) [28]. The absorbed water can hydrolyze the silane bond that is used to couple resin with fillers, de-bond the resin-filler interface and thus reduce the mechanical strengths with time [28]. That may be why the unmodified composite showed a decrease in CS after conditioning in water for 30 days. Regarding the QAB- modified composite, the significant decrease in CS should be attributed to the hydrophilic nature of the $\mathrm{QAB}$ incorporated. As compared to two hydroxyl groups on BisGMA, two QAB groups attached to the newly synthesized oligomer would absorb water even more aggressively because of the ionic charges they carry $[27,28]$. These ionic charges can accelerate the interfacial de-bonding. That may be why a dramatic reduction in CS was observed. Unlike those QAS-modified dental glass-ionomer cements [29], the above negative effect to dental resin composites should be cautiously weighed while the positive effect of QAS is beneficial in reducing bacteria. In our previous work related to glass-ionomer cements, we found that QAS did not degrade the cement during the 30-day aging although it reduced the initial strength as well [29].

Finally we compared YS, M, CS, DTS, FS and antibacterial activity between unmodified and modified composites. The QAB-modified composite was 20 and $55 \%$ in YS, 14 and $46 \%$ in modulus, 34 and $43 \%$ in CS, 29 and $46 \%$ in DTS and 27 and $37 \%$ in FS lower than the unmodified composite, respectively, in dry and wet states. On the other hand, however, the QAB-modified composite was much higher (37\% higher) in antibacterial activity than the unmodified composite.

\section{CONCLUSIONS}

We have synthesized several novel QAB-containing oligomers and used them for formulation of antibacterial resin composites. All the QAB-modified composites showed significant antibacterial activity and mechanical strength reduction. It was found that increasing chain length and loading significantly enhanced the antibacterial activity but also dramatically reduced the CS. The 30-day aging study showed that the incorporation of the QAB accelerated the degradation of the composite, suggesting that the QAB may not be well suitable for development of antibacterial dental resin composites or at least the QAB loading should be well controlled, unlike its use in dental glass-ionomer cements. The authors believe that the work in this study is beneficial and valuable to those who are interested in studying antibacterial dental resin composites.

\section{ACKNOWLEDGEMENTS}

This work was sponsored by NIH challenge grant (RC1) DE020614. Ms. Cunge Zheng was acknowledged for her assistance in MIC testing.

\section{REFERENCES}

[1] Mjor, I.A., Dahl, J.E. and Moorhead, J.E. (2002) Placement and replacement of restorations in primary teeth. Acta Odontologica Scandinavica, 60, 25-28. doi:10.1080/000163502753471961

[2] Forss, H. and Widstrom, E. (2004) Reasons for restorative therapy and longevity of restorations in adults. Acta Odontologica Scandinavica, 62, 82-86. doi:10.1080/00016350310008733

[3] Manhart, J., Godoy, F.G. and Hickel, R. (2002) Direct posterior restorations: clinical results and new developments. Dental Clinics of North America, 46, 303-339. doi:10.1016/S0011-8532(01)00010-6

[4] Deligeorgi, V., Mjor, I.A. and Wilson, N.H. (2001) An overview of reasons for the placement and replacement of restorations. Primary Dental Care: Journal of the Faculty of General Dental Practitioners, 8, 5-11.

[5] Wiegand, A., Buchalla, W. and Attin, T. (2007) Review on fluoride-releasing restorative materials-Fluoride release and uptake characteristics, antibacterial activity and influence on caries formation. Dental Materials, 23, 343-362. doi:10.1016/j.dental.2006.01.022

[6] Osinaga, P.W., Grande, R.H., Ballester, R.Y., Simionato, M. R., Rodrigues, C.R.D. and Muench, A. (2003) Zinc sulfate addition to glass-ionomer-based cements: Influence on physical and antibacterial properties, zinc and fluoride release. Dental Materials, 19, 212-217. doi:10.1016/S0109-5641(02)00032-5

[7] Takahashi, Y., Imazato, S., Kaneshiro, A.V., Ebisu, S., 
Frencken, J.E. and Tay, F.R. (2006) Antibacterial effects and physical properties of glass-ionomer cements containing chlorhexidine for the ART approach. Dental Materials, 22, 647-652.

[8] Yamamoto, K., Ohashi, S., Aono, M., Kokybu, T., Yamada, I. and Yamauchi, J. (1996) Antibacterial activity of silver ions implanted in $\mathrm{SiO} 2$ filler on oral streptococci. Dental Materials, 12, 227-229. doi:10.1016/S0109-5641(96)80027-3

[9] Syafiuddin, T., Hisamitsu, H., Toko, T., Igarashi, T., Goto, N., Fujishima, A. and Miyazaki, T. (1997) In vitro inhibition of caries around a resin composite restoration containing antibacterial filler. Biomaterials, 18, 1051- 1057. doi:10.1016/S0142-9612(97)88072-6

[10] Gottenbos, B., Mei, H.C., Klatter, F., Nieuwenhuis, P. and Busscher, H.J. (2002) In vitro and in vivo antimicrobial activity of covalently coupled quaternary ammonium silane coatings on silicone rubber. Biomaterials, 23, 1417-1423. doi:10.1016/S0142-9612(01)00263-0

[11] Thebault, P., Givenchy, E.T., Levy, R., Vandenberghe, Y., Guittard, F. and Geribaldi, S. (2009) Preparation and antimicrobial behavior of quaternary ammonium thiol derivatives able to be grafted on metal surfaces. European Journal of Medicinal Chemistry, 44, 717-724. doi:10.1016/j.ejmech.2008.05.007

[12] Imazato, S., Russell, R.R. and McCabe, J.F. (1995) Antibacterial activity of MDPB polymer incorporated in dental resin. Journal of Dentistry, 23, 177-181. doi:10.1016/0300-5712(95)93576-N

[13] Murata, H., Koepsel, R.R., Matyjaszewski, K. and Russell, A.J., (2007) Permanent, non-leaching antibacterial surfaces-2: How high density cationic surfaces kill bacterial cells. Biomaterials, 28, 4870-4879. doi:10.1016/j.biomaterials.2007.06.012

[14] Lu, G., Wu, D. and Fu, R. (2007) Studies on the synthesis and antibacterial activities of polymeric quaternary ammonium salts from dimethylaminoethyl methacrylate. Reactive and Functional Polymers, 67, 355-366. doi:10.1016/j.reactfunctpolym.2007.01.008

[15] Lee, S.B., Koepsel, R.R., Morley, S.W., Matyjaszewski, K., Sun, Y. and Russell, A. J. (2004) Permanent, nonleaching antibacterial surfaces. 1. Synthesis by atom transfer radical polymerization. Biomacromolecules, 5, 877-882. doi:10.1021/bm034352k

[16] Li, F., Chai, Z.G., Sun, M.N., Wang, F., Ma, S., Zhang, L., Fang, M. and Chen, J.H. (2009) Anti-biofilm effect of dental adhesive with cationic monomer. Journal of Dental Research, 88, 372-376. doi:10.1177/0022034509334499

[17] Li, F., Chen, J., Chai, Z., Zhang, L., Xiao, Y., Fang, M. and Ma, S. (2009) Effects of a dental adhesive incorporating antibacterial monomer on the growth, adherence and membrane integrity of Streptococcus mutans. Journal of Dentistry, 37, 289-296.

\section{doi:10.1016/i.jdent.2008.12.004}

[18] Beyth, N., Farber, I.Y.Y., Bahir, R., Domb, A.J. and Weiss, E.I. (2006) Antibacterial activity of dental composites containing quaternary ammonium polyethyleneimine nanoparticles against Streptococcus mutans. Biomaterials, 27, 3995-4002. doi:10.1016/j.biomaterials.2006.03.003

[19] Beyth, N., Yudovin-Farberb, I., Perez-Davidia, M., Domb, A.J. and Weiss, E.I. (2010) Polyethyleneimine nanoparticles incorporated into resin composite cause cell death and trigger biofilm stress in vivo. Proceedings of the National Academy of Science, 107, 22038-22043. doi:10.1073/pnas.1010341107

[20] Xie, D., Chung, I-D., Wang, G. and Mays, J. (2006) Synthesis and evaluation of novel bifunctional oligomerbased composites for dental applications. Journal of Biomaterials Applications, 20, 221-236.

[21] Xie, D., Chung, I.-D., Wang, G., Feng, D. and Mays, J. (2004) Synthesis, formulation and evaluation of novel zinc-calcium phosphate-based adhesive resin composite cement. European Polymer Journal, 40, 1723-1731. doi:10.1016/j.eurpolymj.2004.03.005

[22] Wei, G.X., Campagna, A.N. and Bobek, L.A. (2007) Factors affecting antimicrobial activity of muc7 12-mer, a human salivary mucin-derived peptide. Annals of Clinical Microbiology and Antimicrobials, 6, 1-10.

[23] Kim, Y., Farrah, S. and Baney R.H. (2007) Membrane damage of bacteria by silanols treatment. Electronic Journal of Biotechnology, 10, 252-259. doi:10.2225/vol10-issue2-fulltext-7

[24] Shackelford, J.F. (2009) Introduction to Materials Science for Engineers. $7^{\text {th }}$ Edition, Pearson Education, Inc., Upper Saddle River.

[25] Wang, G., Weng, Y., Chu, D., Xie, D. and Chen, R. (2009) Preparation of alkaline anion exchange membranes based on functional poly(ether-imide) polymers for potential fuel cell applications. Journal of Membrane Science, 326, 4-8. doi:10.1016/i.memsci.2008.09.037

[26] Dermaut, W., van den Kerkhof, T., van der Veken, B.J., Mertens, R. and Geise, H.J. (2000) Cold stretching of PPV with water as a plasticizer. Macromolecules, 33, 5634-5637. doi:10.1021/ma992062j

[27] Lio, K., Minoura, N. and Nagura, M. (1995) Swelling characteristics of a blend hydrogel made of poly (allylbiguanido-co-allylamine) and poly(vinyl alcohol). Polymer, 36, 2579-2583.

doi:10.1016/0032-3861(95)91204-K

[28] Drummond, J.L. (2008) Degradation, fatigue, and failure of resin dental composite materials. Journal of Den- tal Research, 87, 710-719. doi: $10.1177 / 154405910808700802$

[29] Weng, Y., Guo, X., Gregory, R.L. and Xie, D. (2010). A novel antibacterial glass-ionomer cement. European Journal of Oral Science, 118, 531-534. 